\title{
Erratum
}

\section{Erratum to: NEW TENSION MECHANISM FOR HIGH-SPEED TENSILE TESTING MACHINE}

\author{
B. RUAN ${ }^{1)}$, G. Q. LI $^{1)^{*}}$, Y. CHEN ${ }^{1)}$, P. MITROUCHEV ${ }^{2)}$, B. HE ${ }^{1)}$ and L. X. LU ${ }^{1)}$ \\ ${ }^{1)}$ Shanghai Key Laboratory of Intelligent Manufacturing and Robotics, Shanghai University, Shanghai 200072, China \\ ${ }^{2}$ Université Grenoble Alpes, G-SCOP, F-38000, Grenoble, France, CNRS, G-SCOP, F-38000 Grenoble, France
}

Erratum to: International Journal of Automotive Technology, Vol. 17, No. 6, pp. 1033-1043 (2016) DOI $10.1007 / \mathrm{s} 12239-016-0101-2$

The corresponding author's e-mail address of the above article should be as follows:

leeching@staff.shu.edu.cn 